\title{
Im Museo Anatomico, Neapel
}

\author{
E. Danieli
}

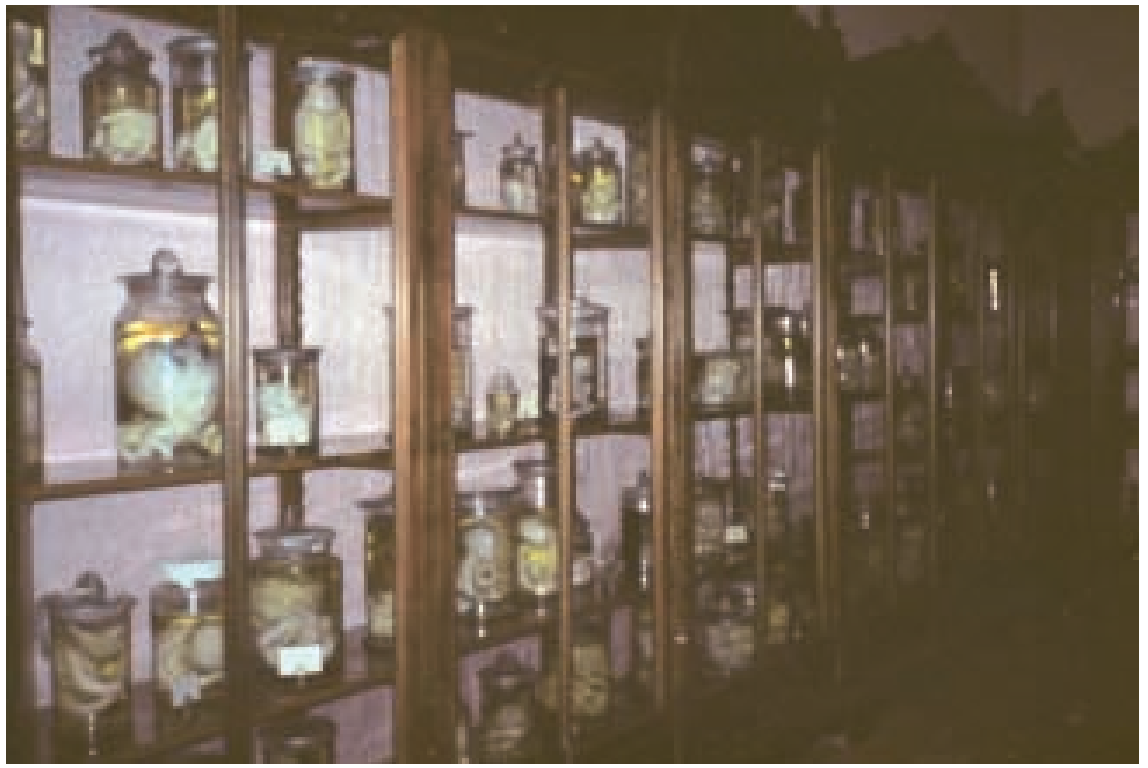

Neapels Unterwelt (Napoli Sotterranea) - ein weitverzweigtes System von Gängen und Schächten, die tief unter den Häusern in den Tuffstein eingegraben sind, von Räumen, Kammern und Zisternen - und damit verbunden der Besuch der unter den Kirchen gelegenen Katakomben und Gräbern mit den eingelagerten Tausenden von Schädeln, dass diese Führung zufällig ganz in der Nähe des Eingangs zum Anatomischen Museum endet.

Das «Museo Anatomico» ist in seiner Art einzigartig. Von Marco Severino im 17. Jahrhundert gegründet, gehöre es zu den bestdotierten Anatomiesammlungen (Le Collezioni) der Welt: So erklärt es der Student, der unsere Gruppe, bestehend aus jungen Japanerinnen und wenigen Amerikanern, durch die Räume des Instituts führt. $\mathrm{Zu}$ lachen gibt es nichts: «Per favore, rispetto al corpo morto, al cadavere!» Andächtig verharren wir vor dem von Andreas Vesalius präparierten Oberarmknochen, stumm versuchen wir der Stimme unseres Führers zu folgen: «Preparati per pietrificazione, le cere anatomiche, corpi imbalsamati, i calcoli, preparazioni a secco, preparazioni cardiovascolari.» Nun folgen die entsprechenden englischen Übersetzungen anatomical waxes, the petrified preperations, the art of embalming, upper limb preparation. Ich habe mich von der Gruppe entfernt, betrachte die missgebildeten Skelette, die lebensgrossen und lebensechten Leichen, ich höre nur noch aus der Entfernung die Stimme des Studenten: "Malformazioni fetali, aborti, gemelli, i mostri, le chimere, le sirene, il minotauro, i grifi, i idri, i ciclopi ...» In einem alten, höhlenartigen Palazzo mit grünbepflanztem Innenhof, benachbart der Poliklinik, befindet sich die vorzügliche Sammlung von eingelagerten Skeletten, von getrockneten Leichen, von Dutzenden von Embryonen und Föten in formalingefüllten, hohen Einweckgläsern, von wächsernen Augen, von Innenohren, von Händen und Füssen, von Herzen, Lebern, Nieren und Lungen, von Missgeburten und vor allem von Hunderten von Schädeln: «... i crani italioti per esempio, ossa, ossa ...» Ausgestellt sind die anatomischen Präparate in barocken, hölzernen, üppig verzierten Vitrinen, in Wandschränken, die selber ein eigenes Museum bilden könnten. «I crani, skulls, ossa di giganti, come una forma delle reliquie nelle antiche 
chiese ...»- die Gruppe hat mich eingeholt - «... i crani di alcuni delinquenti giustiziati, condannato della capitazione ... heads preserved by desiccation ...» Ich betrachte die wie lebend wirkenden wächsernen Männerköpfe mit unzähligen Schnitt-, Stich- und Schussverletzungen: «Ceroplastica», lese ich auf dem Emailschild, «di teste di camorristi». «Queste teste sono di un realismo sorprendente, danno una chiara documentazione delle ferite che si riscontravano sul volto dei camorristi!»

Ich habe genug gesehen, ich verzichte auf die Fortsetzung, will nichts mehr hören von «non meno interessanti sono i preparati di organi della riproduzione, apparato genitale femminile, feti con gravi mostruosità». Und noch während die Stimme weiter berichtet von «unica è la collezione di centocinquante pietre ...», schliesse ich die schwere Türe hinter mir und verlasse eilenden Schrittes die Räume der Universität. In den engen Gassen von Spaccanapoli, der blaue Himmel ist nur handtuchbreit $\mathrm{zu}$ sehen, erwarten mich Kinder, die, zum Teil maskiert, zu wilder Trompeten-, Tschinellen- und Trommelmusik einen Maskentanz aufführen. Ich schliesse mich der musizierenden Gruppe an, gehe als Hinterster. Mir kommt in diesem Moment dieses ekstatische Leben, dieser Kindermaskenzug, als Rettung vor, ich folge ihm mit fest geschlossenen Lidern. Erst spät bemerke ich, dass zu meiner Linken ein schon älteres Kind in einem schwarzen, bodenlangen Hosenanzug und mit einer weissen Maske und mit einer Sense über der Schulter neben mir hergeht und dann sich bei mir einhakt. 